\title{
APPLIED ULTRASONIC CLEANING AND POWDER DISPERSION
}

\author{
T. Lee \\ J. W. Williams \\ C. W. Weber
}

\section{OAK RIDGE GASEOUS DIFFUSION PLANT} OAK RIDGE, TENNESSEE

\section{prepared for the U.S. ATOMIC ENERGY COMMISSION}

under U.S. GOVERNMENT Contract W.7405 eng 26

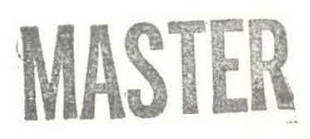




\section{DISCLAIMER}

This report was prepared as an account of work sponsored by an agency of the United States Government. Neither the United States Government nor any agency Thereof, nor any of their employees, makes any warranty, express or implied, or assumes any legal liability or responsibility for the accuracy, completeness, or usefulness of any information, apparatus, product, or process disclosed, or represents that its use would not infringe privately owned rights. Reference herein to any specific commercial product, process, or service by trade name, trademark, manufacturer, or otherwise does not necessarily constitute or imply its endorsement, recommendation, or favoring by the United States Government or any agency thereof. The views and opinions of authors expressed herein do not necessarily state or reflect those of the United States Government or any agency thereof. 


\section{DISCLAIMER}

Portions of this document may be illegible in electronic image products. Images are produced from the best available original document. 


\section{Printed in the United States of America. Available from National Technical Information Service \\ U.S. Department of Commerce \\ 5285 Port Royal Road, Springfield, Virginia 22151}

Price: Printed Copy $\$ 4.00$; Microfiche $\$ 0.95$

This report was prepared as an account of work sponsored by the United States Government. Neither the United States nor the United States Atomic Energy Commission, nor any of their employees, nor any of their contractors, subcontractors, or their employees, makes any warranty, express or implied, or assumes any legal liability or responsibility for the accuracy, completeness or usefulness of any information, apparatus, product or process disclosed, or represents that its use would not infringe privately owned rights. 


\section{APPLIED ULTRASONIC CLEANING \\ AND POWDER DISPERSION}

T. Lee, J. W. Williams, * and C. W. Weber

Chemical Analysis Department Laboratory Division

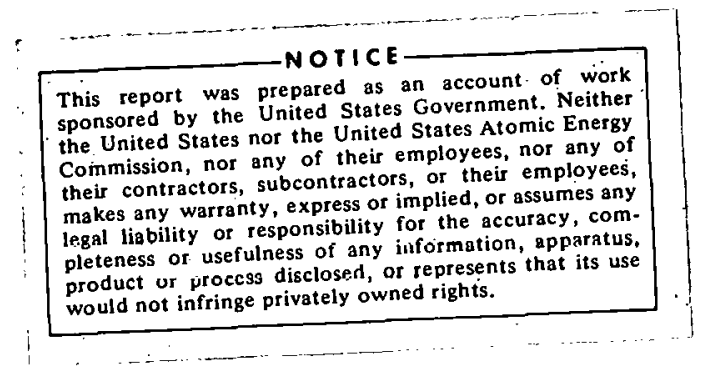

Oak Ridge Gaseous Diffusion Plant

Union Carbide Corporation

Dak Ridge, Tennessee.

Prepared for the U. S. Atomic Energy Commission under U. S. Government Contract W-7405 eng 26

*Presently located at the Y-12 Plant. 
0

\section{THIS PAGE \\ WAS INTENTIONALLY \\ LEFT BLANK}

- 
ABSTRACT

The application of ultrasonics to a wide range of cleaning and powder dispersion requirements is demonstrated. With orientation toward understanding the applications discussed in this report, a description of the equipment and a relatively simple treatment of the theory are included. In the sections describing the applications to cleaning and to powder dispersions, several innovations are included to provide uniform cleaning without erosion, multiple powder-sample dispersions, and tests for effective cleaning and for complete powder dispersion. The ultrasonic applications included cleaning small valve parts and large liquid centrifuge components, decontaminating simulated reactor fuel elements, and degreasing parts for subsequent plating. They also included. dispersing powders for analytical and preparative purposes. 


\section{THIS PAGE \\ WAS INTENTIONALLY \\ LEFT BLANK}


CONTENTS

$\underline{\text { Page }}$

INTRODUCTION AND SUMMARY . . . . . . . . . . . . . . . . 9

EQUIPMENT . . . . . . . . . . . . . . . . . . . . . 9 9

Tank and Transducers . . . . . . . . . . . . . . 9

Generator . . . . . . . . . . . . . . . . . . 11

THEORY . . . . . . . . . . . . . . . . . . . . 11

Standing Wave Pattern . . . . . . . . . . . . 13

Cavitation .. . . . . . . . . . . . . . . . 13

Resonance : . . . . . . . . . . . . . . . . 13

Multiples of $\lambda / 2$. . . . . . . . . . . . . . . 17

Depth for Cleaning Applications ........... . 17

Depth for Powder Dispersion . . . . . . . . . . . 17

Effect of Physical Properties of the Liquid Medium . . . . 18

Outgassing of the Liquid Medium . . . . . . . . . . 18

Pressure Over the Liquid . . . . . . . . . . . . . 18

Ultrasonic Activity and Forces . . . . . . . . . . 18

ULTRASONIC CLEANING . . . . . . . . . . . . . . . . . . 19

Scrubbing Action . . . . . . . . . . . . . . . . 19

Test for Scrubbing Action . . . . . . . . . . . . 19

Uniform Cleaning Without Erosion Damage . . . . . . . . 20

Extension Tank for Large Objects . . . . . . . . . . . 24

Cleaning Liquids .. . . . . . . . . . . . . 24

CLEANING APPLICATIONS .................... . . . . 24

Ultrasonic Cleaning of Cadmium Discs .. . . . . . . . 24

Ultrasonic Preparation. of Steel for Electroless Nickel

Plating . . . . . . . . . . . . . . . . . . 26

Ultrasonic Cleaning of Teflon Valve Seats . . . . . . . . 26

Ultrasonic Cleaning of Liquid Centrifuge Parts . . . . . : 26

Ultrasonic Decontamination of Simulated Fuel Elements for

the Transuranium Chemical Process (TRU-Project) . . . : . . 27

Initial Tests with Aluminum Rods . . . . . . . . . . 27

Stearic Acid Removal from Simulated TRU-Project Fuel

Elements . . . . . . . . . . . . . . . 27

Radioactive Decontamination of Simulated TRU-Project

Fuel Elements ................. 27

Ultrasonic Cleaning of Fuel Rods for the rRU-Project . . . 28

ULTRASONIC DTSPERSION . . . . . . . . • . . . . . . . . 29

Sample Preparation .................. . . 30

Sample Size . . . . . . . . . . . . . . . . . . 30

Multiple-Sample Dispersion . . . . . . . . . . . . 30

Usable Quantities of Powder . . . . . . . . . . . . 32

Ultrasonic Exposure Period . . . . . . . . . . . . . . 32

Cooling During Ultrasonic Exposure . . . . . . . . . 32 


\section{THIS PAGE}

\section{WAS INTENTIONALLY LEFT BLANK}


CONTENTS, Continued

$\underline{\text { Page }}$

DISPERSION APPLICATIONS ............... 34

Ultrasonic Dispersion of Alumina for Particle Size Distribution and Slurry Preparation with Limited Particle Size . 34

Ultrasonic Dispersion of Kaolinite Clay for Particle Size

Distribution and Powder Preparation with Limited Particle

Size ................. . . . 34

Ultrasonic Dispersion for Particle Size Distribution . . 34

Ultrasonic Dispersion for Preparing Limited Size

Fractions . . . . . . . . . . . . 35

ACKNOWLEDGMENTS . . . . . . . . . . . . . 35

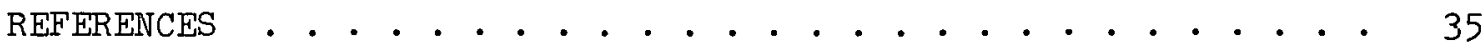


THIS PAGE

\section{WAS INTENTIONALLY LEFT BLANK}


\begin{tabular}{l} 
APPLIED ULTRASONIC CLEANING \\
AIND POWDER DISPERSION \\
\hline
\end{tabular}

INTRODUCTION AND SUMMARY

The use of ultrasonics in a variety of cleaning and powder dispersion problems has resulted in improved results. Ultrasonics applied to a number of cleaning problems provided significant savings and, in some cases, cleaning which could not be achieved by other means. Ultrasonic dispersion of powders was needed for particle size distribution determinations, 1 and for preparing usable quantities of powders with specific particle size ranges. A 20-kc, 1000-watt ultrasonic liquid bath was used for both applications.

Proper application of ultrasonics requires an understanding of the design of the equipment, and the basic ultrasonic theory involved. With orientation toward understanding the applications discussed in this report, a description of the equipment and a relatively simple treatment of the theory are included. In the sections describing the applications to cleaning and to powder dispersions, several innovations are included to provide uniform cleaning without erosion, multiple powder-sample dispersions, and tests for effective cleaning and for complete powder dispersion. The ultrasonic applications included cleaning small valve parts and large liquid centrifuge components, decontaminating simulated reactor fuel elements, and degreasing parts for subsequent plating. They also included dispersing powders for analytical and preparative purposes. It is believed that others might benefit from these demonstrations in their ultrasonic applications.

\section{EQUIPMENT}

A 20-kc, 1000-watt ultrasonic system was used for the cleaning and powder dispersion applications. The system consisted of a tank, a bank of magnetostrictive transducers, and a radio frequency generator. The tank was stainless steel, rectangular in shape, with inside dimensions $11-1 / 2 \times 9$ $\mathrm{x} 8 \mathrm{in}$. high. The system is shown in figure 1.* (Positioned on top of the tank is a reciprocating engine and suspension assembly described in a later section under Uniform Cleaning Without Erosion Domage.)

TANK AND TRANSDUCERS

The magnetostrictive transducers, which are attached to the outside bottom of the tank, are basically electromagnets. The cores are designed to produce maximum dimensional changes by the alternating magnetic field

*The identification of specific brand names in this report is not meant to be limiting. Other equipment with equal specifications may work equally well. 
PHOTO NO. PH-66-1679

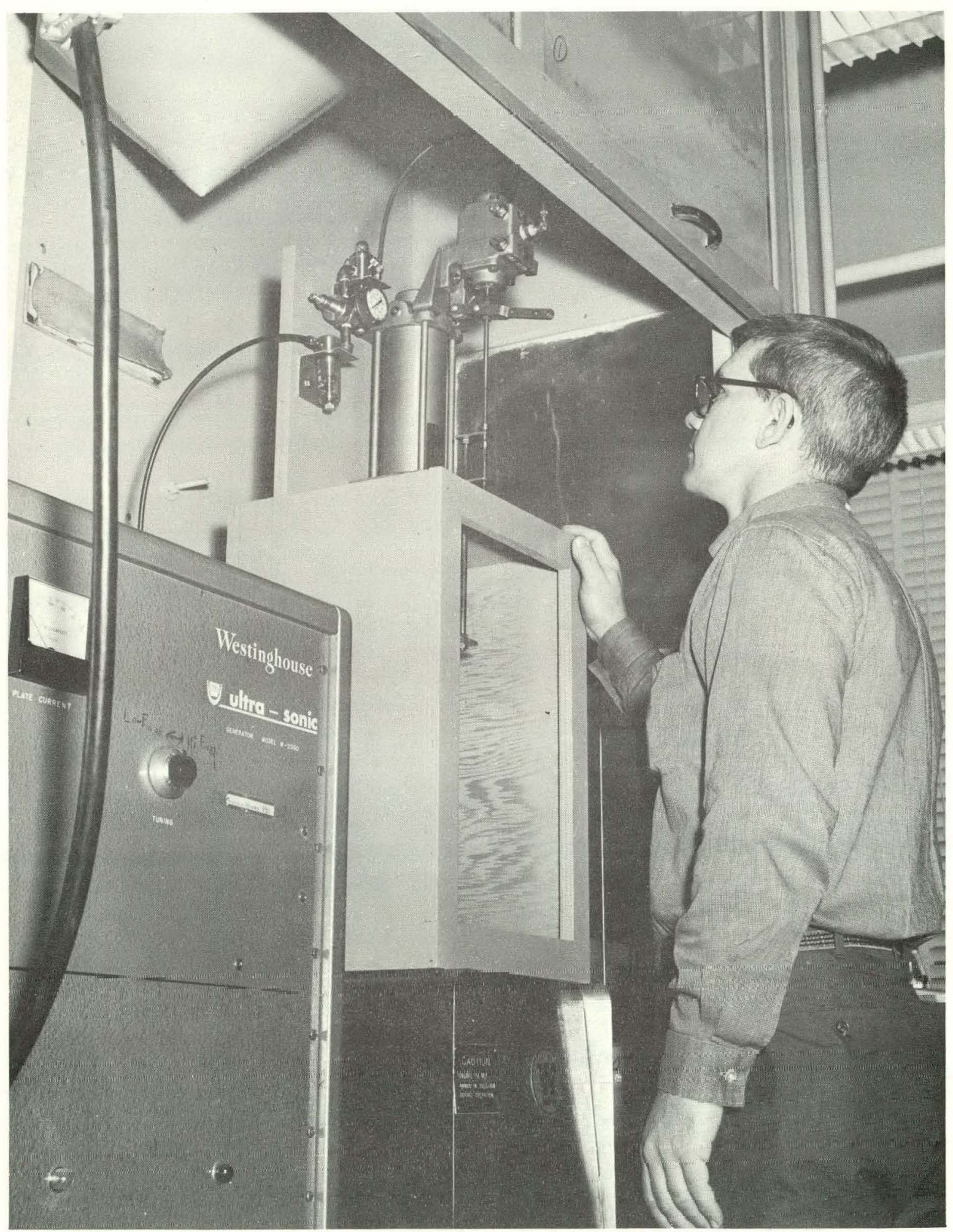

Figure 1

20-KC ULTRASONIC SYSTEM 
produced by the 20-kc rf current flowing through the transducer coils. The 20-kc mechanical oscillations in the core are transmitted to produce similar oscillations in the tank bottom, from which the sonic energy is transmitted to the liquid above.

\section{GENERATOR}

A schematic of the basic $20-k c$ radio frequency generator circuit is shown in figure 2. Tuning is provided from 18 to $22 \mathrm{kc}$. Power is controlled with a variable transformer in the primary of the high-voltage transformer. A dc or polarizing current, which also flows through the transducer coils, prevents oscillation at twice the designed frequency at half amplitude. ${ }^{*}$ The amplitude is important, since it determines the intensity of the ultrasonic energy and, to a large degree, the effectiveness of the ultrasonic treatment. Since the efficiency of magnetostrictive transducers drops off rapidly with increasing frequency, 3 the double frequency, which would occur without the polarizing current, would further reduce the amplitude of the ultrasonics.

\section{THEORY}

Ultrasonic cleaning and powder dispersion utilize the tremendous forces generated by the collapsing of minute bubbles in the liquid medium. These vapor bubbles are formed by the ultrasonic energy literally tearing the liquid apart. The process of bubble formation and collapse is referred to as cavitation. The theory associated with the formation and collapse of the bubbles, and the understanding of patterns and energies in the ultrasonic tank have led to efficient application of the resultant forces to cleaning and to powder dispersion.

*The magnitude of the magnetostrictive effect without a dc polarizing current is a function of the peak ac current measured from zero independent of polarity. A superimposed dc current greater than the peak ac current shifts the ac current above zero. Under these conditions, the magnetostrictive effect becomes a function of the peak ac current measured between the top and bottom peaks. Thus the dc polarizing current, in effect, doubles the magnitude of the magnetostrictive effect and the resulting sonic amplitude.

The polarizing current also affects the sonic frequeili:y. The number of sonic pulses per second, or frequency, generated by the magnetostrictive transducer is a function of the number of build-up and decay cycles of the current flowing through the transducer independent of polarity. Without a dc polarizing current, there is a current build-up and decay cycle above zero, and a current build-up and decay cycle below zero for each electrical cycle. Thus the sonic frequency would be twice the electrical frequency. With a dc polarizing current, however, there is only one current build-up and decay cycle for each electrical cycle, resulting in a sonic frequency equal to the electrical frequency. 
DWG. NO. G-73-666

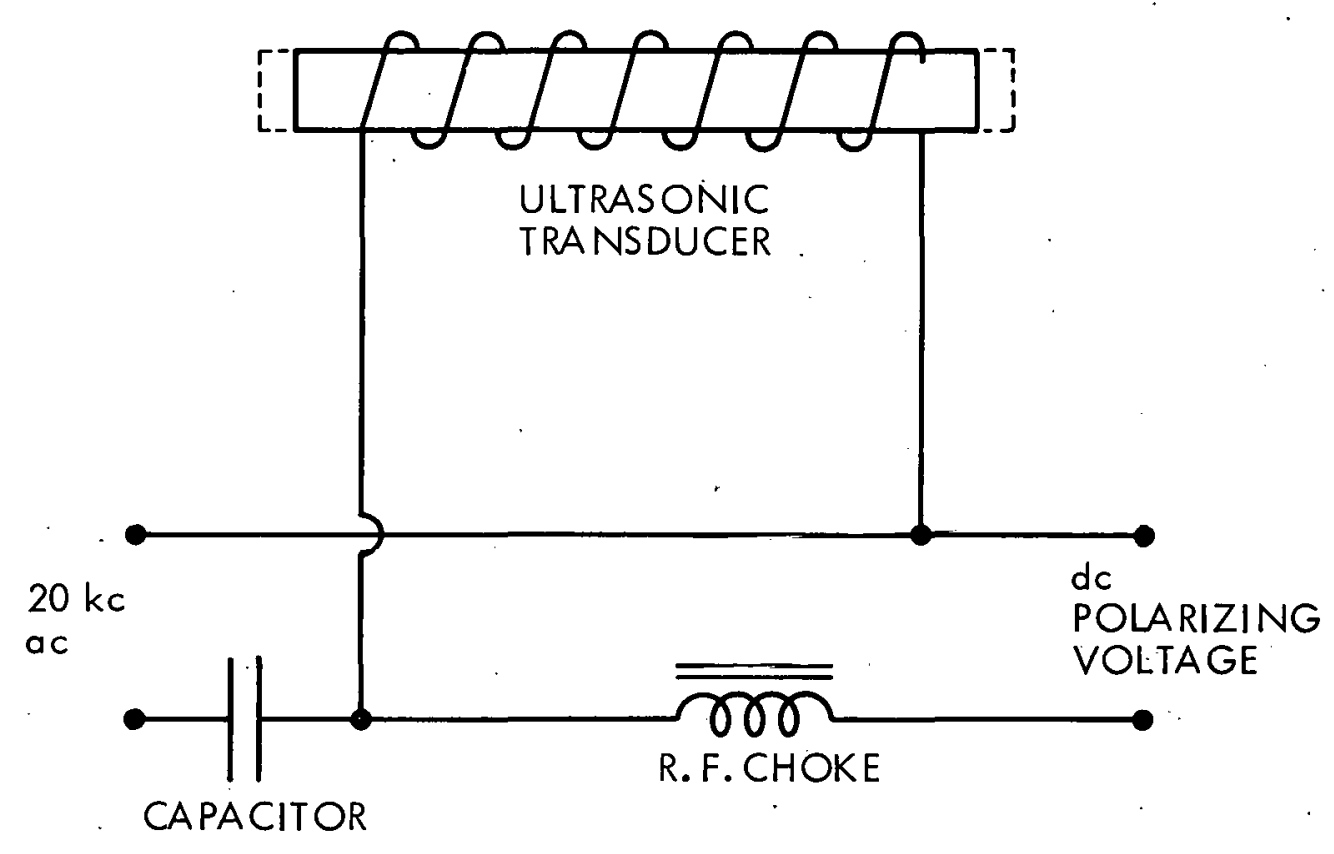

Figure 2

BASIC ULTRASONIIC EIRCUII. 


\section{STANDING WAVE PATTERN}

The piston-like* oscillations of the tank bottom, in contact with the transducers below and the liquid above, produce sonic waves in the liquid by alternate compressions and expansions of the liquid in the direction of travel, which is away from the source. Since the source (transducers) is located at the bottom of the tank in the equipment used, the waves travel from the bottom of the tank to the surface of the liquid. At the surface (liquid-air interface), $99.9 \%$ of the sonic energy is reflected toward the bottom of the tank. 4 At the bottom, the waves are again reflected, this time toward the surface.

When the liquid depth is properly controlled, the waves reflected at the bottom are in phase with, and, therefore, reinforce the waves emitted by the transducers. Thus, there are waves traveling in opposite directions: from the bottom of the tank toward the surface, and from the surface toward the bottom. These waves moving in opposite directions combine to form, by interference, a standing wave pattern, as shown in figure 3 . At those levels where the waves are in phase, they enhance one another to form vibration maxima ( $a, b, c, d$, and $e$ in figure 3 ). Where the waves are 180 degrees out of phase, vibration minima are formed ( $f, g, h$, and $i$ in figure 3 ).

\section{CAVITATION}

The properties of the sonic bath at the vibration maxima and minima are different. At vibration maxima, the molecules of the liquid medium undergo maximum movement due to the sonic energy alternately forming compressions and rarefactions. However, very little ultrasonic cleaning or dispersion occurs at those levels, because the forces involved are relatively weak. At vibration minima, where more concentrated forces exist, the liquid is torn apart by the oppositely-phased (both upward and downward) forces acting through the liquid. It is at those levels, where cavitation occurs, that ultrasonic cleaning action and powder dispersion are most effective.

\section{RESONAINCE}

Standing waves, which are required for cavitation** with the equipment used, are formed when the reflecting surface is a whole number of half-wavelengths,

*The oscillations of the tank bottom are diaphragm-like, producing slightly diverging sonic waves. The theory, however, is based on pistonlike oscillations producing parallel waves.

* Cavitatiun can also occur without standing waves during the rarefaction part of the wave cycle if sufficient sonic energy is available. 'l'he required energy may be provided by high power transducers and generators, or by concentrating the energy of lower power units with acoustic lenses or solid horns (velocity transformers). These techniques, which were not employed in the present study and are beyond the scope of this report, arc described in standard texts dealing with ultrasonics. 
DWG. NO. G-73-56

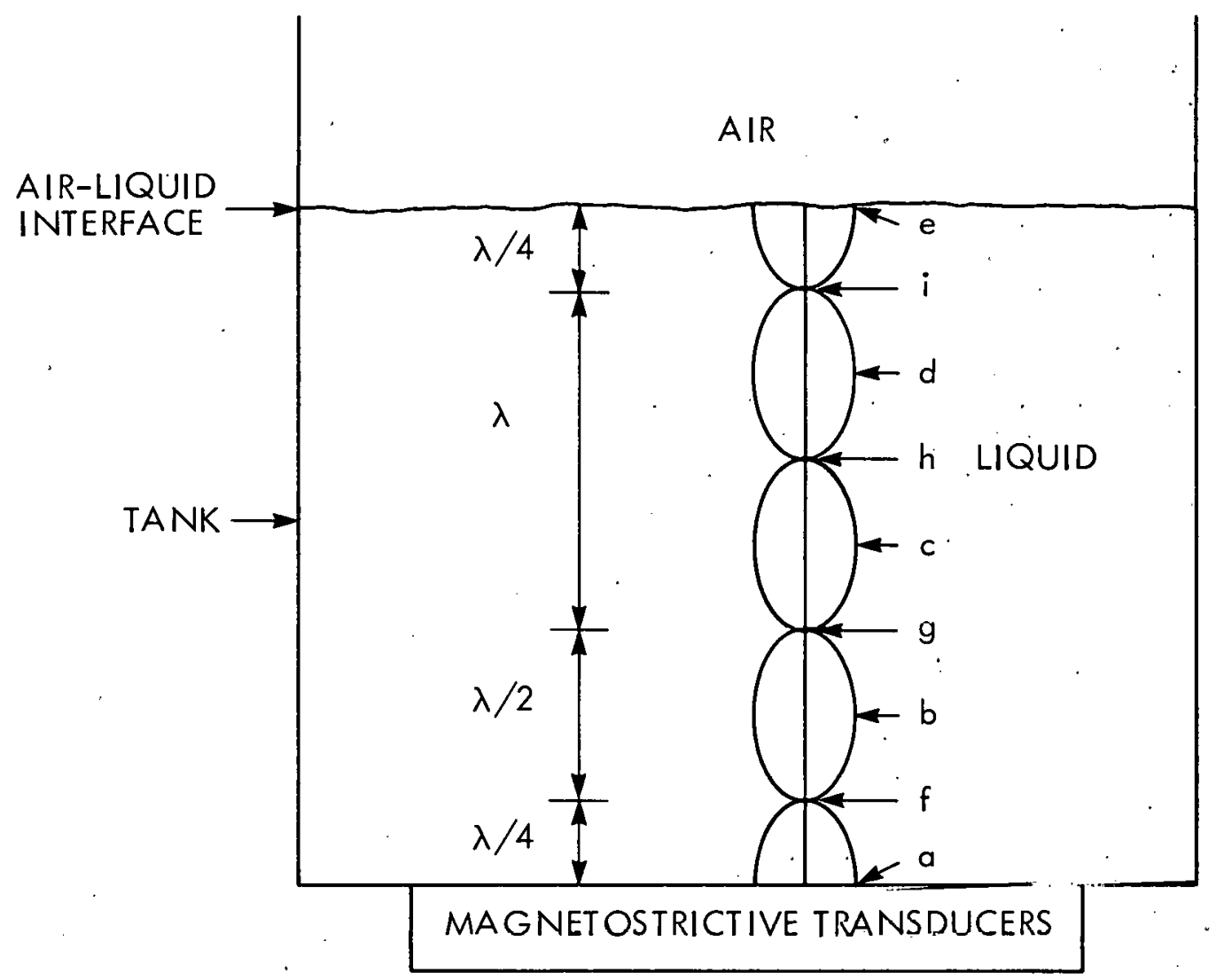

Figure 3

STANDING ULTRASONIC WAVES 
$\lambda / 2$, from the source (transducers). Under those conditions, the phase requirements for vibration maxima and minima at specific levels, as shown in figure 3, are satisfied. The half-wavelength, or distance between successive vibration maxima or successive vibration minima, is a function of the frequency and velocity of the sound waves, according to the following relationship:

$$
\lambda=\frac{c}{f}
$$

where
$c$ is the velocity of the sound in the medium,
$f$ is the frequency of the sound, and
$\lambda$ is the wavelength.

The velocity of sound in water 5 at $36^{\circ} \mathrm{C}$ is $6 \times 10^{4} \mathrm{in} . / \mathrm{sec}$. Since the nominal frequency of the equipment used in the application was $20 \mathrm{kc}$, the wavelength in water, according to the above relationship, is $3 \mathrm{in.}$, and the half-wavelength is $1-1 / 2$ in. By adjusting the liquid depth to a wholenumber multiple of $1-1 / 2$ in.*, the resonant frequency of the liquid matches the 20-kc operating frequency of the generator and transducers, to provide maximum energy transfer. Since cavitation occurs at the levels of vibration minima, cavitation will be observed at $1-1 / 2-i n$. intervals starting $3 / 4$ in. from the tank bottom and $3 / 4$ in. from the liquid surface. The standing-wave pattern for a $1-1 / 2-i n$. depth $(\lambda / 2)$ with its single cavitation level is shown in figure 4. Figure 3 shows the pattern for a 6-in. depth (four half-wavelengths) with four cavitation levels.

It is often convenient to carry out ultrasonic cleaning operations or powder dispersions in thin-wall, stainless-steel containers positioned inside the ultrasonic tank. The coupling liquid between the tank and the small containers may be different from that used in the containers. Different media may also be used in each of the small containers. For the most effective ultrasonic cleaning or dispersion, the liquid depths of the various liquids in the containers and of the coupling liquid must be adjusted to whole number multiples of $\lambda / 2$. If water is used as the coupling liquid or in any of the containers, the $\lambda / 2$-depth will, of course, be $1-1 / 2 \mathrm{in}$. at $20 \mathrm{kc}$. For other media, optimum depths are based on the velocities of sound in the respective media. Where the velocities are not known, the depths may be determined as discussed in the footnote cited in the previous paragraph.

\footnotetext{
*Multiples of 1-l/2 in. liquid depth, for the 20-kc frequency, applies to water at $36^{\circ} \mathrm{C}$. Other liquids, in which sound travels at other velocities, will resonate at the same frequency at other depths. Those depths can be calculated from the velocity of sound in the liquid, or experimentally determined by adjusting the depth for maximum ultrasonic activity, indicated by maximum loading of the generator and maximum cavitation or transducer sound.
} 


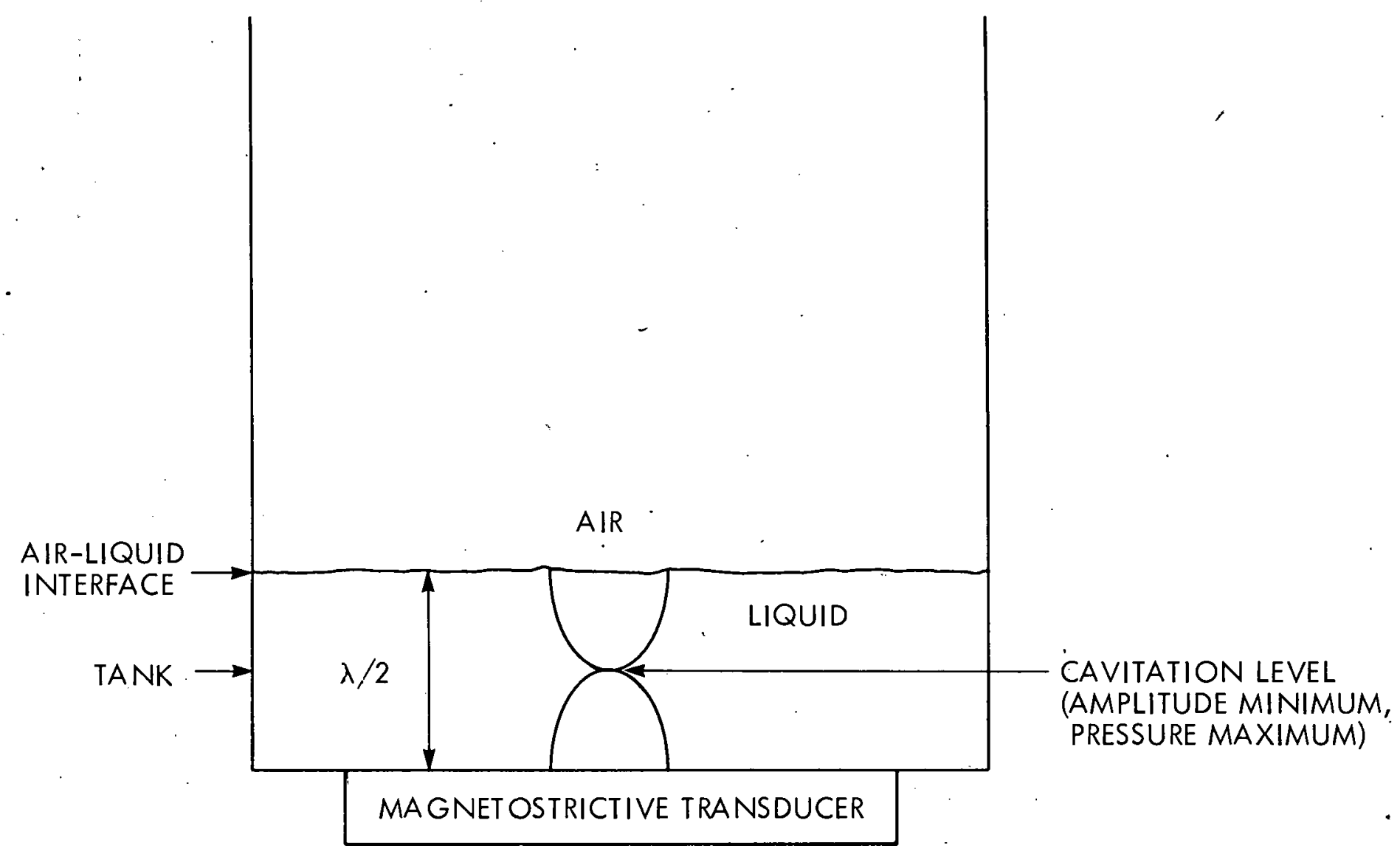

Figure 4

STANDING WAVE PATTERN FOR SINGLE CAVITATION LEVEL 
The liquid depth adjustments are normally made as if the containers are not present. The container walls have essentially no effect on the sonic waves if the wall thickness is small compared to the sonic wavelength. 6,7 The stainless steel containers used have a wall thickness of about 0.035 in., which is small compared to the sonic wavelength of 3 in.

MULTIPLES OF $\lambda / 2$

The energy at each cavitation level depends upon the sonic output from the transducers and the number of cavitation levels (depth in terms of multiples of $\lambda / 2$ ). For a given transducer output, the sonic energy is divided among the cavitation levels. Thus the most concentrated cavitation will occur using a depth of $1-1 / 2$ in. $(\lambda / 2)$. As the number of halfwavelengths (depth) is increased, the cavitation at any level will be reduced.*

Depth for Cleaning Applications

The minimum depth (in units of $\lambda / 2$ ) required to cover the object was used for cleaning applications. The minimum depth provided the most concentrated cavitation and the most effective ultrasonic cleaning (see also Uttrasonic Activity and Forces).

Depth for Powder Dispersion .

Puwder dispcrsion involves two opposing factors: suspension concentration, and cavitation near the tank bottom. By using a depth of $\lambda /{ }^{\prime 2}$ ( $\operatorname{single}$ cavitation level), all cavitation activity is concentrated near the bottom of the tank $(\lambda / 4=3 / 4-i n$. for $20-k c$ in water $)$. This tends to minimize powder settling. Diluting the suspension, however, minimizes reagglomeration of the powder once it has been dispersed. Such dilution, obtained by increasing the liquid depth in whole-number multiples of $\lambda / 2$, would reduce the cavitation activity near the bottom of the tank. Thus, there may be an optimum depth for any given powder system, and an evaluation of that optimum is recommended. In the present work, however, only single cavitation depths were used for dispersion (see also Ultrasonic Activity and Forces).

The suspension concentration, of course, also can be reduced by decreasing the powder sample size. The minimum sample size for particle size distribution determinations, however, is limited by the precision requirements for determining the solids-content of the effluent size-fractions (see sample Size).

*This process will continue until the cavitation threshold is reached. Below the threshold, cavitation ceases. In practice, however, the threshold limit does not appear to be a limitation. With the 1000watt, 20-kc system, cavitation was observed'with liquid depths of 18 in. or 12 half-wavelengths (obtained with an extension tank described in a later seciliul under ULtraconia Cleaning). 
EFFECT OF PHYSICAL PROPERTIES OF THE LIQUID MEDIUM

The forces generated by cavitation depend upon the physical properties of the liquid medium. Those forces increase with increasing surface tension and decreasing vapor pressure of the liquid medium. ${ }^{8}$ Viscosity, which plays only a secondary effect on the cavitation forces, is of lesser importance. Organic media, which generally have lower surface tensions and higher vapor pressures than water, will generate lower cavitation forces. Detergents, soaps, or other surface-active materials, which may be added to aqueous systems, lower the surface tension, resulting in lower cavitation forces. These additives, however, may provide physicochemical forces which are very important in cleaning, and in certain powder deagglomeration and dispersion applications. In practice, a satisfactory combination of the two types of forces should be provided for optimum application.

\section{OUTGASSING OF THE LIQUID MEDIUM}

The cavitation forces initially observed in a liquid medium are significantly less than those observed after about 30 minutes of ultrasonic exposure. This initial reduction in cavitation forces is due to dissolved gases, which are driven off by the ultrasonic activity. 9 In this work, therefore, for quantitative evaluations and for powders which have a tendency to settle, the liquid medium was exposed to the ultrasonic field for 30 minutes before the powder or object was introduced to the bath.

Outgassing sharpens the resonance of the system. Accordingly, during outgassing and after introducing the powder or object to the bath, resonance of the generator with the bath is readjusted. When large objects are introduced, the liquid depth is also readjusted.

\section{PRESSURE OVER THE LIQUID}

The pressure above the liquid affects the forces generated by the cavitation process. For a given ultrasonics bath system, there is a pressure at which the forces are maximum. ${ }^{10}$ Thus it may be possible to obtain more effective ultrasonic action, not only in water but in organic media, by operating the system at the optimum pressure. Although an evaluation of pressure effects was not made for the applications involved in this study, such an evaluation would be recormended for some problems, particularly for dispersing powders which are not reasonably dispersable in aqueoustype media.

\section{ULTRASONIC ACTIVITY AND FORCES}

The mechanism of ultrasonic cavitation has not been fully established.ll It is the authors' opinion, however, that for a given bath system, once the cavitation threshold is reached, additional ultrasonic energy primarily increases the number of cavitation sites (i.e., the level of activity). The cavitation forces remain essentially the same, increasing only very slowly with increasing ultrasonic energy. This concept tends to be supported by the increased ultrasonic activity observed in organic 
liquids with low surface tensions and high vapor pressures; these properties are known to result in low cavitation forces (see Effect of the Physical Properties of the Liquid Medium).

If the above concept is correct, the difference between a liquid depth of $\lambda / 2$ (with a single cavitation level) and a liquid depth of multiples of $\lambda / 2$ (with multiple cavitation levels) is primarily the result of the distribution of the cavitation activity. Ultrasonic cleaning in depths greater than the required minimum (see Depth for Cleaning Applications) removes part of the cavitation activity from the immediate vicinity of the object being cleaned. Reduced activity under these conditions decreases the rate of cleaning, and may impair the cleaning operation. In powder deagglomeration and dispersion, removing part of the cavitation activity from the cavitation level near the tank bottom (see Depth for Powder Dispersion) by increasing the liquid depth (see figures 3 and 4) would reduce the turbulence generated by the cavitation near the botton of the tank, and mily allow the powder to settle out from the regions of cavitation. Powder settling during the ultrasonic treatment results in impaired deagglomeration and dispersion.

\section{ULTRASONIC CLEANING}

\section{SCRUBBING ACTION}

Ultrusonic cleaning, like other kinds of cleaning, involves solvent and chemical actions, and scrubbing action by mechanical means. The solvent and chemical action are provided by the medium in which the object is being cleaned, and by added surfactants or other chemicals. The scrubbing action in ultrasonic cleaning is provided by the explosion-like forces generated by the collapse of the minute bubbles formed during cavitation.

The effect of ultrasonic bath temperature has'not been specifically studied for the applications to be discussed in this report. However, it is recognized that solvent actions and chemical reaction generally increase with temperature, their rates often approximately doubling with each $10^{\circ} \mathrm{C}$ increase. It is also recognized that increasing the temperature increaces the vapor pressure and decreases the surface tension, thus decreasing the effectiveness of the ultrasonic scrubbing action.12 Thus for each cleaning application there will be an optimum temperature. Most operations in this study were carried out initially at room temperature, the bath temperature rising several degrees with use; this benefited the sleaning.

\section{Test for Scrubbing Action}

Cavitation and the resulting ultrasonic scrubbing action should, according to theory, occur at 1-1/2-in. intervals in the system used with water. The intensity of the scrubbing action should range from a maximum at each amplitude minimum, to a minimum at each adjacent amplitude maximum (see previous section Cavitation and figure.3). Since cavitation is turbulent 
in distribution, sharp divisions between maximum and minimum scrubbing areas would not be expected. In addition, objects in the bath would perturb the pattern.

To determine the actual distribution and degree of uniformity of the scrubbing action in the bath, a stainless steel rod was coated with red wax, and positioned vertically (at right angles to the cavitation levels) in the aqueous bath. No solvents or cleaning agents were used, since the objective was not to clean the rod, but to obtain an indication of the effectiveness and distribution of the ultrasonic scrubbing action. The wax was removed at 1-1/2-in. intervals, confirming that the scrubbing action is not uniform in the bath, but occurs at the levels of cavitation (vibration minima). As expected, the divisions between levels of wax removed (scrubbing action) were somewhat irregular.

Having established that the intensity of the scrubbing action forms a periodic pattern at right angles to the levels of cavitation (see figure 3 ), tests were made to determine the scrubbing pattern at and between cavitation levels. The tank was filled with water to a depth of 3 in. which is equivalent to two half-wavelengths, to provide two levels of cavitation. The stainless steel rod (1/2-in. dia), coated with red wax as in the preceding vertical tests, was positioned in the bath horizontally (parallel to the cavitation levels). With the rod at the bottom of the tank, a band along the top of the rod (side away from the transducer, but facing the cavitation region) was scrubbed. With the rod centered in the region of maximum cavitation, only spotty scrubbing was obtained on the sides of the rod. Positioning the rod midway between two cavitation levels provided spotty scrubbing on the top and bottom of the rod. Above the midposition between the two cavitation levels, scrubbing occurred in a narrow band along the top; below the midposition, scrubbing occurred along the bottom. In all cases, scrubbing was irregular and incomplete. Figure 5 shows the rod coated with wax before ultrasonic exposure. Figure 6 shows the rod after a 3-minute exposure positioned horizontally near the bottom of the tank.

\section{UNIFORM CLEANING WITHOUT EROSION DAMAGE}

Depending upon the properties of the contaminants and of the object being cleaned, erosion damage could occur without completely cleaning the specimen where the scrubbing action (cavitation) is strong. To provide uniform cleaning without erosion damage, the object was moved up and down through the cavitation levels.13 The up-and-down motion was obtained with an airoperated reciprocating engine positioned over the bath as shown in figure 1. Large objects were suspended in the bath directly from the reciprocating piston. Small objects were placed on a tray similarly suspended from the piston. The engine was adjusted to operate at about 6 cycles per minute with an amplitude of about 2 in. (a little greater than $\lambda / 2$ ). Such up-and-down movement uniformly exposed all surfaces of the object to the regions of ultrasonic scrubbing, providing uniform cleaning action, as shown in figure 7. Experience with delicate parts showed that this technique avoided erosion damage by the bath. 
PHOTO NO. PH-66-1680

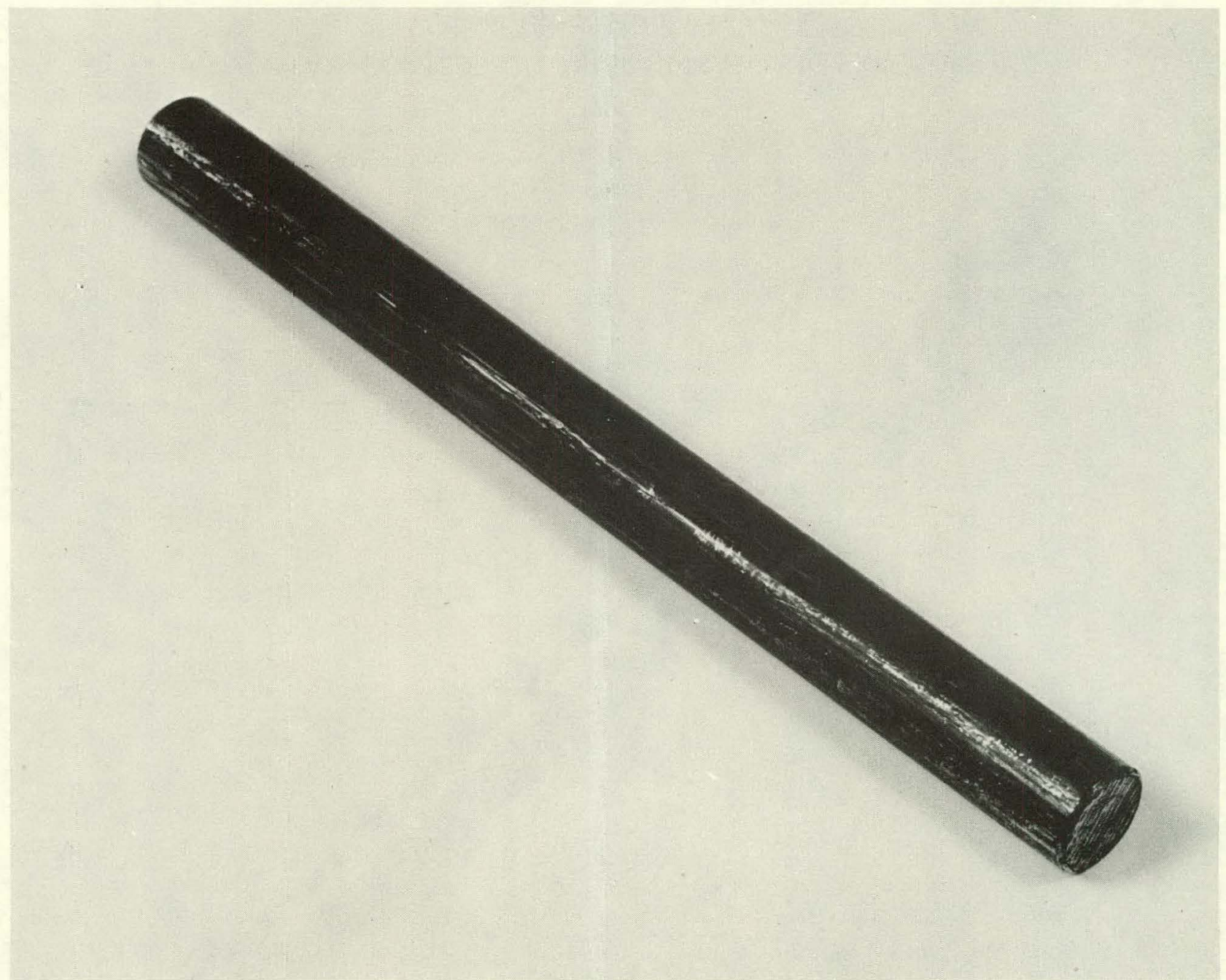

Figure 5

STEEL ROD COATED WITH WAX BEFORE ULTRASONIC EXPOSURE 


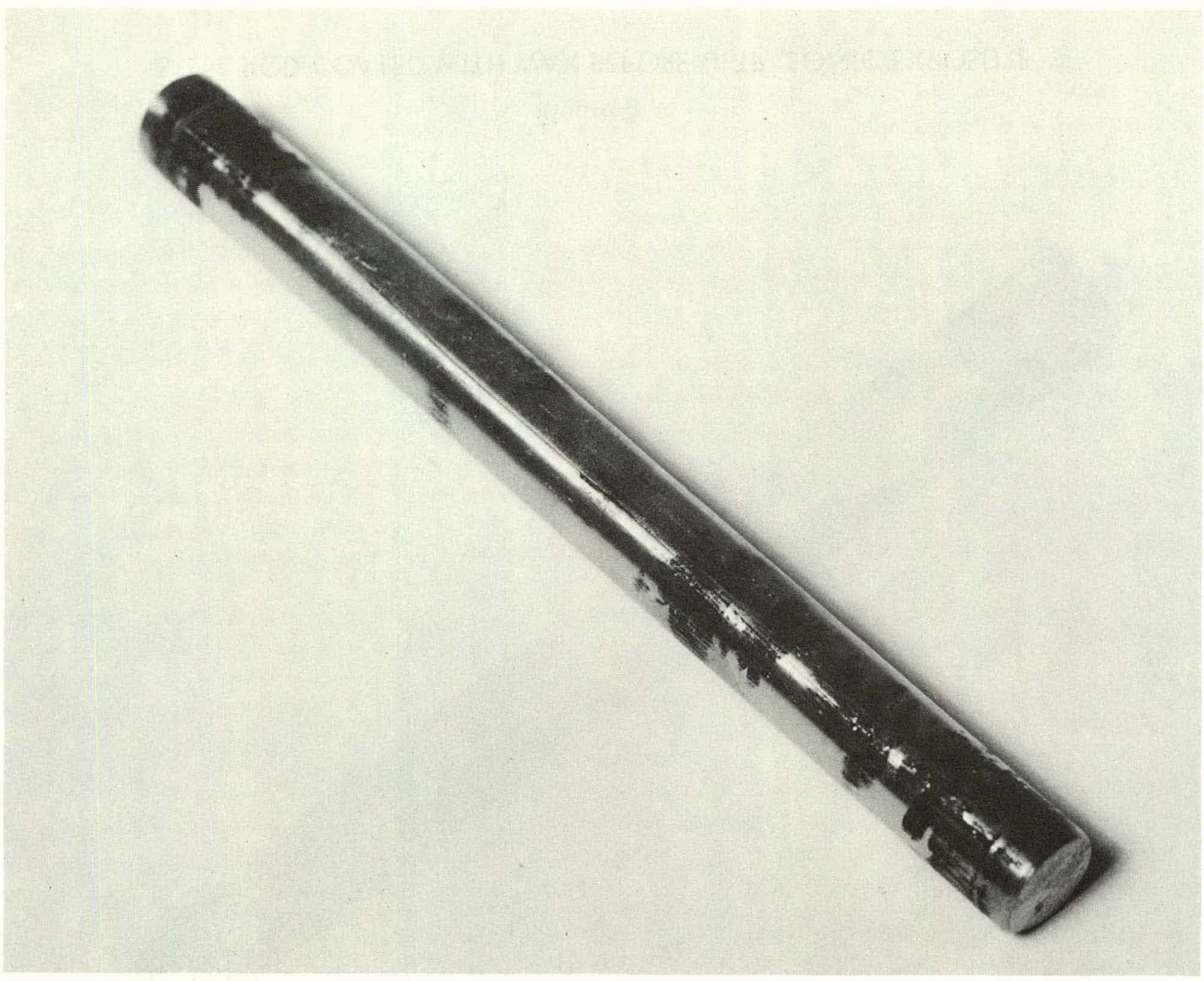

Figure 6

WAX-COATED ROD AFTER ULTRASONIC EXPOSURE

Without Up-and-Down Movement 
PHOTO NO. PH-66-1681

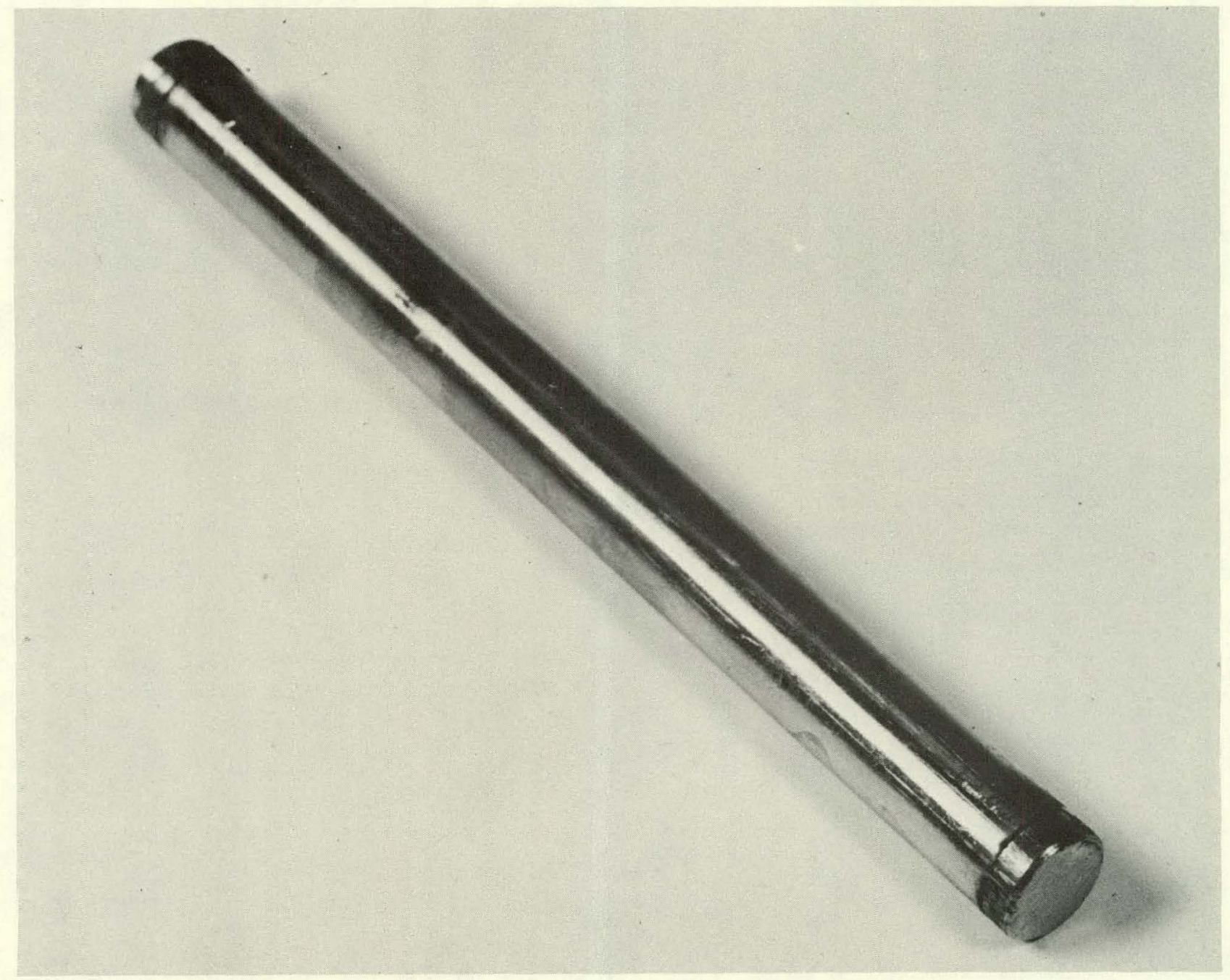

Figure 7

WAX-COATED ROD AFTER ULTRASONIC EXPOSURE

With Up-and-Down Movement 
EXTENSION TANK FOR LARGE OBJECTS

To clean some objects larger than the tank depth, an extension tank with a 24-inch depth was used. The extension tank was positioned inside the ultrasonic tank on rubber stoppers $1-1 / 2$ inches thick $(\lambda / 2)$, as shown in figure 8. The $\lambda / 2$ of liquid between the two tank bottoms served to transfer the ultrasonic energy from the transducers to the liquid in the extension tank. The 3-inch liquid depth $(2 \lambda / 2)$ between the sides of the two tanks provides a reservoir to assure liquid coupling between the tank bottoms. The depth of the liquid in the extension tank was adjusted to provide the minimum number of whole-number multiples of $\lambda / 2$ (whole-number multiple of $1-1 / 2 \mathrm{in}$. for water at $20 \mathrm{kc}$ ) required to cover the object to be cleaned. The reciprocating piston, previously described, was also applicable with the extension tank, to provide uniform cleaning without erosion of the object.

\section{CLEANING LIQUIDS}

The cleaning medium, including the addition of any cleaning agents, is selected for each application. Since the medium with the most effective chemical forces does not necessarily provide the most cffective ultrasonic forces, there should be one or more media which are most effective for any given ultrasonic cleaning application. In practice, however, an exhaustive examination is not always made, particularly where only a limited number of samples are to be cleaned. The medium is selected simply to meet the needs of each cleaning operation, as illustrated by the following applications.

\section{CLEANING APPLICATIONS}

'l'he cleaning applications to be dcscribed illustrate the theory and methods applied to a number of requests originating at ORGDP and elsewhere.

\section{ULTRASONIC CLEANING OF CADMIUM DISCS}

An ultrasonic cleaning procedure was developed for cleaning small (approx. 3/4-in. dia) cadmium discs. The clean discs were to be shaped into hemispheres to be used in neutron detectors for area dosimeters.

The 20-kc, 1000-watt ultrasonic cleaning system was applied. The discs were placed in the bottom of a glass beaker positioned on the bottom of the ultrasonic cleaning tank. Of several cleaning baths examined, dilute nitric acid appeared most effective. With 5-minute ultrasonic exposures, and a $0.016 \mathrm{~N} \mathrm{HNO}_{3}$ bath, effective cleaning was obtained, with less than 0.0001 in. of material loss (thickness). (The allowable material loss was 0.001 in.) The 5-minute exposure was assumed optimum for effective cleaning, minimum material loss, and economy of time. Cleaning the discs in batches of 100 required the addition of make-up acid to the $750 \mathrm{ml}$ of bath solution during the 5-minute ultrasonic exposure. Measurements of $\mathrm{pH}$ indicated that adding the make-up acid at the rate of $0.1 \mathrm{ml}$ of concentrated $\mathrm{HNO}_{3}$ per minute was satisfactory. Adding the total make-up acid prior to the ultrasonic exposure removed excessive cadmium from the dises. 
DWG. NO. G-73-54

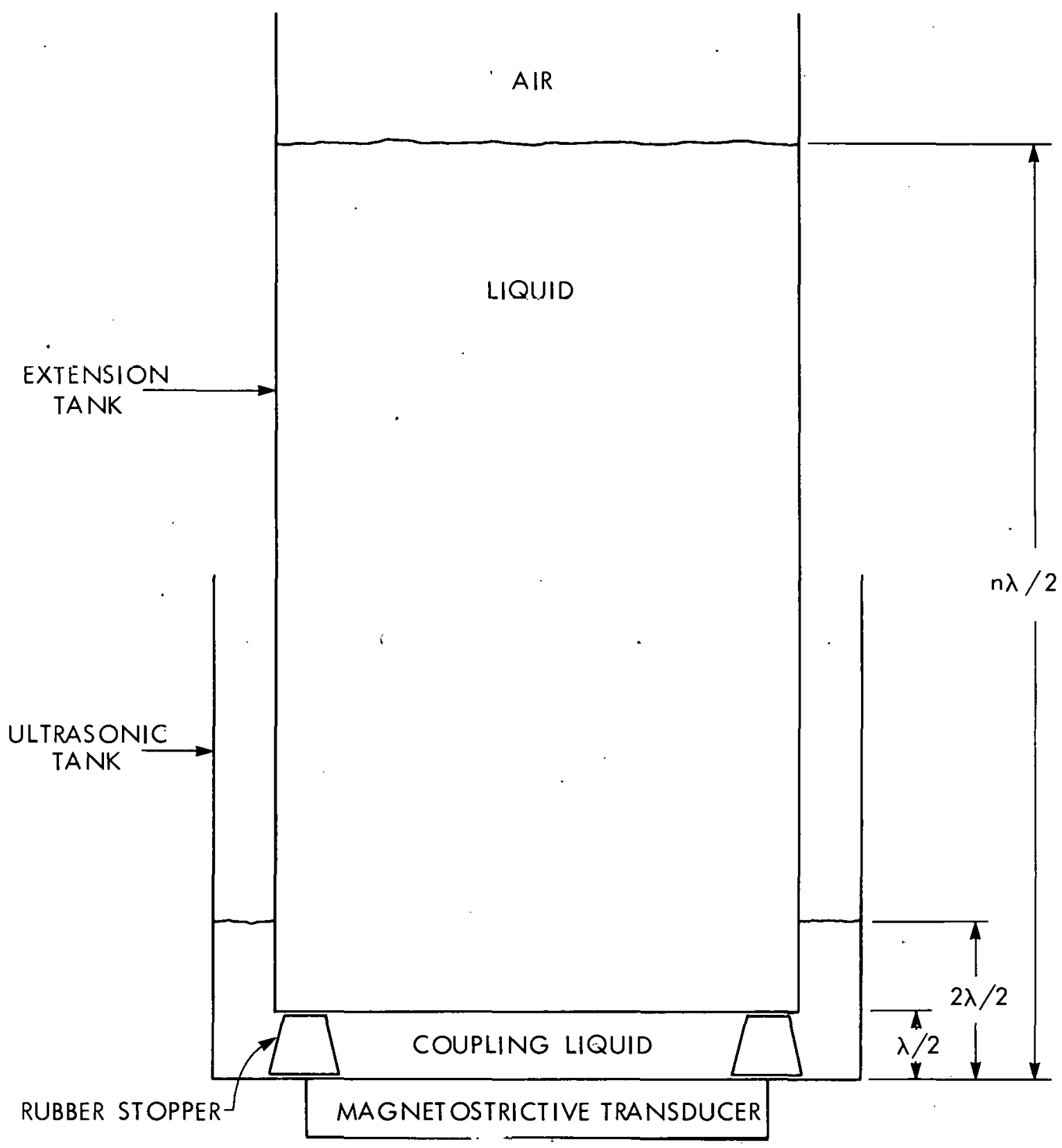

Figure 8

EXTENSION TANK POSITIONED INSIDE ULTRASONIC TANK 
Prewashing the discs to remove surface oil was not necessary. Tests consistently gave equivalent results with or without prewashing, indicating that the surface oil was adequately removed, giving no interference.

In batches of 100 discs, only 12 minutes of effort was required for each cleaning operation. Several hundred discs were cleaned for this project.

\section{ULTRASONIC PREPARATION OF STEEL FOR ELECTROLESS NICKEL PLATING}

The surface of high carbon steel balls was successfully prepared for electroless nickel plating, by controlled exposures in the 20-kc ultrasonic bath. Several batches of small steel samples were degreased in an ultrasonic bath at elevated temperatures, using trichloroethylene. After degreasing, the samples were held under alcohol to prevent air exposure, then transferred to an ultrasonic bath containing dilute hydrochloric acid. The surface showed the desired grey luster within 5-10 minutes, depending on the acid concentration. The grey luster was uniform, attributed to rotation of the balls by the ultrasonic agitation during the exposures. The samples were rinsed and again protected from air (by being submerged in alcohol) prior to plating. After plating, microscopic examination showed the surface to be free from pits or other irregularities.

\section{ULTRASONIC CLEANING OF TEFLON VALVE SEATS}

Due to particulate (grit) scoring, the Teflon seats used in ball valves had to be reconditioned by lapping against the aluminum ball from the valve. Particles of metal and lapping compound became embedded in the face, causing leakage and wear of the assembled valves.

Chemical leaching methods proved successful in the removal of lapping and polishing compound from the Teflon faces. An ultrasonic bath was used to intimately contact the embedded particles with the leaching solutions. Trace material remaining was deeply embedded and expected to present no operating problems.

In the ultrasonic bath, an initial hydrofluoric acid treatment removed most of the foreign material. Subsequently, aqua regia and $50 \%$ sodium. hydroxide solutions removed most of the remaining material. Due to the chemical inertness of Teflon, such pieces can be cleaned in the ultrasonic bath with a minimum of attention and effort.

\section{ULTRASONIC CLEANING OF LIQUID CENTRIFUGE PARTS}

A preliminary evaluation was made for ultrasonically cleaning liquid centrifuge parts. The parts were associated with the ORNL program conducted in the $\mathrm{K}-703$ Building in the former ORGDP Powerhouse area. The intricate design of the parts, with narrow passages contaminated with solid deposits of cesium chloride, sucrose, serum, and cell tissue presented a. time-consuming manual cleaning operation. Tests made with several aqueous cleaning solutions and with trichlorotrifluoroethane (Refrigerant-113) indicated that these parts could be cleaned ultrasonically with minimum effort. 
For routine cleaning, it was recommended that erosion of the parts, which could not be tolerated, be controlled to a minimum by continually moving the parts through the cavitation levels, using the vertical reciprocating system. To accommodate larger centrifuge parts, an extension tank was proposed.

ULTRASONIC DECONTAMINATION OF SIMULATED FUEL ELEMENTS FOR THE TRANSURANIUM CHEMICAL PROCESS (TRU-PROJECT)

Initial Test With Aluminum Rods

The surfaces of type 1100 aluminum rods were successively and rapidly decontaminated by exposure in the 20-kc ultrasonic bath. Several batches of aluminum rods of two sizes ( $1 / 4$ in. dia. $x 1 / 2$ in. long, and $3 / 8$ in. dia. $x 6$ in. long) were decontarninated in the bath using a preheated saturated water solution of Decon 4306-C.* The temperature of the bath during the ultrasonic treatment was $68^{\circ} \mathrm{C}$.

The rods had varying degrees of surface roughness and (for test purposes) were deliberately contaminated by rubbing with $\mathrm{UF}_{4}$ powder, to simulate contaminated reactor fuel elements. Decontamination (to background levels) was effected in the ultrasonic bath in 1-2 minutes for the large rods with relatively rough surfaces, and 2 seconds for the small rods with smoother surfaces. Surface radioactivity was measured in this and the. following tests with a survey-type, portable counter. Without ultrasonics, decontamination of all pieces was incomplete even after 1 hour of soaking in the cleaning bath.

Stearic Acid Removal From Simulated TRU-Project Fuel Elements

Stearic acid, embedded in accordion-like folds on the sides of reactor fuel elements (simulated components for the Transuranium Chemical Process), was successfully and rapidly removed by exposure in a 20-kc ultrasonic bath. The folds were formed during the pressing and sealing operation, when the length of the fuel elements was reduced from 1 to $1 / 2$ in. Stearic acid, used as a lubricant for the operation, had to be removed to decontaminate the surfaces. Several batches of simulated fuel elements were exposed for 5-, 1-, and 1/2-minute periods in the 20-kc ultrasonics bath containing either dilute sodium hydroxide or dilute trisodium phosphate solutions. Microscopic examination indicated complete removal of stearic acid for the $1-$ and 5-minute exposures. The 1/2-minute exposure did not reach the deepest parts of the folds. Without ultrasonics, the stearic acid was removed only from the outer surface of the folds, even a,ter 30-minute soakings in the solutions.

Radioactive Decontamination of Simulated TRU-Project Fuel Elements

A set of 10 TRU-Project simulated fuel elements were wiped with UF 4 prior to pressing down from 1 in. to approximately $1 / 2 \mathrm{in}$. long. The alpha

*A commercial cleaner; Turco Products Div,--Purex Corp. I.t.d., Houston, Texas. 
contamination was deliberately employed to simulate more nearly the actual cleaning problems to be encountered in the TRU fuel element process. After forming, the 10 elements were divided into two groups of five each for specified cleaning tests. The initial average alpha count was 65 counts/ minute/group.

Group I was ultrasonically cleaned for 1-1/2 minutes using a 6-oz/gal water solution of Alconox* at $68^{\circ} \mathrm{C}$. These elements came out bright and shiny with no measurable alpha contamination.

Group II was soaked without ultrasonics for $1-1 / 2$ minutes in a $0.6-0 z / g a l$ water solution of $\mathrm{NaOH}$ at $68^{\circ} \mathrm{C}$. While these parts had a gray, cleanlooking appearance with no measurable alpha contamination, microscopic examination indicated the lack of cleaning penetration into the folds, as achieved with Alconox in the ultrasonics bath. In addition, the $\mathrm{NaOH}$ solution is extremely corrosive and hard to handle compared to Alconox, which is a commercial detergent and wetting agent.

The preceding tests indicate that ultrasonics is required to penetrate and effectively clean the fuel element surface folds and, in conjunction with Alconox, effectively removes embedded $\mathrm{UF}_{4}$ contamination, without the corrosive action of sodium hydroxide.

\section{ULTRASONIC CLEANING OF FUEL RODS FOR THE TRU-PROJECT}

After cleaning, the actual TRU-project fuel elements are inserted in hollowed-out rods. The fuel rods thus assembled must also be cleaned and decontaminated. According to the design of the proposed project ultrasonic system, the fuel rods, which are $3 \mathrm{ft}$ long by $3 / 8 \mathrm{in}$. in diameter, would be inserted into a simple tank constructed of stainless steel square tubing. This tank would be extended through the opposing walls of an outer tank containing an immersible transducer. Liquia in the outer tark woula couple the ultrasonic energy from the trunsducer to the cleaning liquid in the inner tank. The double-tank arrangement reduces the volume of contaminated wash solution, since only the liquid in the inner tank contacts the fuel rods. Because the fuel elements inside the rods are highly radioactive, the cleaning must be conducted remotely behind heavy shielding. Ultrasonics uniquely provides the remote scrubbing action needed without introducing additional mechanical complications.

An evaluation was conducted to find the most uniform and effective ultrasonic scrubbing or cleaning action. The actual cleaning of TRU fuel rods would involve one or more detergents or ultrasonic cleaning agents. For this evaluation, which was similar to Tests for Scmbbing Action previously described, no cleaning agent was used. Inert fuel rods, of typical design but $l l$ in. long and fabricated to fit the ultrasonic equipment, were coated with red wax and exposed horizontally to the ultrasonic field in a water medium. The objective here, as in earlier tests was not to remove the wax,

*Standard Scientific Supply Company, New York, N. Y. 
but to use the wax removal as a measure of the uniformity and effectiveness of the ultrasonic scrubbing action. This information had to be known to properly design the ultrasonic equipment for the TRU-project.

The 1000-watt, 20-kc ultrasonic tank was filled to a depth of 3 in., which is equivalent to two half-wavelengths. The inert fuel rod, coated with wax, was placed horizontally at the bottom of the tank, and exposed to the ultrasonic field for 3 minutes. A narrow band along the top of the rod (side away from the transducer, but facing the cavitation region) was cleaned. The results were similar to those obtained previously under Tests for Scrubbing Action using solid aluminum rods. Other positions in the standing wave pattern were also examined. With the rod raised into the region of maximum cavitation, only spotty cleaning was obtained on the two sides. Raising the rod midway between the two zones of cavitation, spotty cleaning was observed on the top and bottom of the rod. Moving the rod above the midpoint provided cleaning in a narrow band along the top of the rod, and moving the rod below the midpoint provided cleaning along the bottom. Of the positions examined, the most effective was with the rod at the bottom of the tank, directly over the transducers. Thus to obtain uniform cleaning with this system, it would be necessary to rotate the rods, or to move the rods up and down through one or more cavitation levels. The rotation technique, however, would be more applicable mechanically to the design and operating requirements of the assembled TRU-project system.

The intensity of the cleaning action was significantly increased by reducing the liquid depth to $1-1 / 2$ in. $(\lambda / 2)$. This was expected of course, since the ultrasunic energy is now concentrated in one level instead of being divided between two levels. The uniformity pattern, however, remained unchanged.

Since the double-tank design of the proposed TRU-project system required that the ultrasonic energy pass through the walls of square stainless steel tubing, an evaluation of the attenuation by such tubing was made. The inert fuel rod, coated with red wax, was inserted into an 11-in. length of 1-in. square stainless steel tubing, and exposed to the ultrasonic field. One-inch square tubing had been specified in the original design of the ullrasunlc system. No wax removal could be obtained, although several positions in the bath were tested. By increasing the size of the tubing to $1-1 / 2$ in., however, which is equivalent to $\lambda / 2$ at $20-k c$, ultrasonic scrubbing without excessive attenuation was achieved.

\section{ULTRASONIC DTSPERSION}

Ultrasonic dispersion, like ultrasonic cleaning, is dependent upon the explosion-like furces generated by cavitation. 'l'he cavitation forces, which are generated in the manner discussed under Theory, break down the powder agglomerates into more basic units, forming a stable suspension. 


\section{SAMPLE PREPARATION}

The powder sample to be dispersed must be wetted by the liquid medium. To assure wetting, sufficient liquid is first added to the powder sample to form a paste. Converting the sample to a paste before dilution has proved to be a practical first step in preparation. The paste is ground for several minutes, and then diluted with the dispersing medium.

\section{SAMPLE SIZE}

The sample size, or more specifically the concentration of the powder in the dispersing medium, is important. When the concentration exceeds a certain maximum, the powder tends to settle to the bottom of the tank,* out of range of the direct cavitation forces. The maximum sample concentration which will remain suspended is not the same for all powders. It is dependent upon the density difference between the powder and the dispersing medium, the size of the particles, and of course, the ultrasonic energy. The allowable concentration increases with decreasing density difference, smaller particle size, and increasing ultrasonic energy. The maximum sample size for the ultrasonic dispersion is taken as that amount of powder which will not settle while exposed to the ultrasonic field.

Low concentrations, besides providing more effective ultrasonic dispersion, also favor more stable suspensions once the powder has been dispersed. For particle-size measurements by sedimentation, which employs an important sample preparation by ultrasonic dispersion, the accuracy of the sedimentation process is also improved with decreasing concentration. In practice, however, the lowest sample concentration that can be used in that measurement is limited by the analytical accuracy required and the analytical technique used for determining the amount of powder in each size traction. In general, samples were dispersed acceptably at concentrations in the region of 2 grams per liter.

\section{MULTIPLE-SAMPLE DISPERSION}

Powders which do not have a strong tendency to settle (density difference between powder and medium is not too large) were dispersed in groups of two or more samples. The dispersions were carried out in stainless steel beakers positioned inside the ultrasonic tank, as shown in figure 9.** The liquid level in each beaker was adjusted to one-half wavelength ( $1-1 / 2$ in. of water at $20 \mathrm{kc}$ ). The liquid in the tank outside the beakers, which was

*The use of mechanical stirring to prevent the powder from settling during the ultrasonic exposure was considered. This technique was not evaluated in this study, however, because the requirements were met with the available ultrasonic energy.

**An arrangement which would minimize dampening of the transducers by the weight of the beakers would be to suspend the beakers from above, or to position the beakers on a plate, supported $\lambda / 2$ above the tank bottom (see figure 8) by rubber stoppers. No suspension arrangement was applied, but is recommended for future evaluation. 
DWG. NO. G-73-81

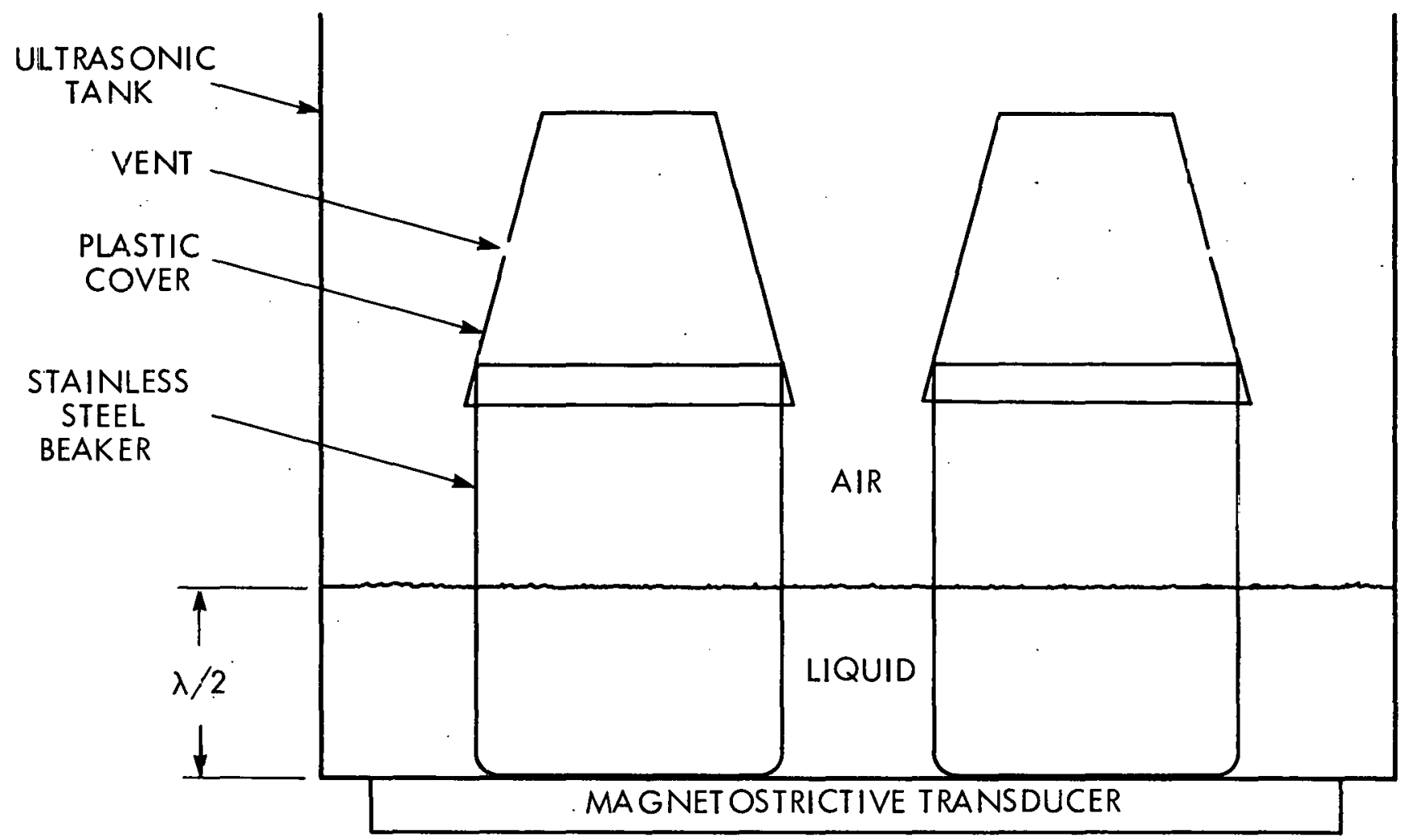

Figure 9

ARRANGEMENT FOR MULTIPLE-SAMPLE DISPERSIONS 
also adjusted to a depth of one-half wavelength, coupled the ultrasonic energy from the transducers at the bottom of the tank to the suspensions inside the beakers (see section under Resonance). The multi-sample dispersion technique was especially useful for comparing the properties of different powders dispersed at the same time, and for dispersing large numbers of samples routinely.

\section{USABLE QUANTITIES OF POWDER}

Usable quantities of powders containing only particles of specified size ranges are sometimes needed. Such powders are conveniently prepared using gravimetric and centrifugal sedimentation techniques preceded by ultrasonic dispersion. To obtain acceptable yields, concentrations significantly greater than those for particle-size measurements are used. For preparative work with powders, the concentrations are selected based on maximum overall yield of the size fraction of interest (established by sedimentation tests) and limited by the practical aspects of the ultrasonic dispersion capability.

\section{ULTRASONIC EXPOSURE PERIOD}

For particle-size measurements, the ultrasonic exposure periods for powder dispersions were established from a study of relative deagglomeration versus ultrasonic exposure time. The study involved exposing a series of sample suspensions of a powder to the 20-kc ultrasonics for selected periods.

After the ultrasonic exposure, the dispersed suspensions were appropriately diluted, and allowed to settle in 13-in. columns for 24 hours. For each ultrasonic exposure period, the powder concentration, determined 1 in. below the suspension surface, provided a measure of the relative deagglomeration. The relative deagglomeration is defined as the concentration at the l-in. depth (after settling) relative to the average concentration of the suspension prior to settling. The l-in. level was selected to provide a convenient sampling point with good sensitivity. As shown in figure 10, the results, which were obtained with alumina, indicate a rapid rate of dispersion during the initial part of the ultrasonic exposure, followed by relatively little change after 16 hours of exposure. This implies that the powder has been deagglomerated to the fullest extent. " The 16-hour schedule conveniently permitted overnight exposure t'or the study of alumina and natural clay dispersions.

\section{COOLING DURING ULTRASONIC EXPOSURE}

Because approximately 16 hours are required to ultrasonically disperse powders, significant quantities of heat are generated by the magnetostrictive transducers attached to the bottom of the tank. A means to cool the suspension during the ultrasonic exposure was provided. A metal cover over the ultrasonic tank served as a vapor condenser. Water flowing through tubing, soldered flat to the metal cover, removed the heat. Vapors from the suspension condensed on the underside of the cover and dripped back into the suspension. The technique thus eliminated the need to add make-up liquid which would have been lost by evaporation. 


$$
\square
$$


Water flowing through coils submersed in the liquid medium was aiso used to cool the suspension. Submersed coils, however, have the disadvantage of being subject to erosion damage by the ultrasonic cavitation.

\section{DISPERSION APPLICATIONS}

ULTRASONIC DISPERSION OF ALUMINA FOR PARTICLE SIZE DISTRIBUTION AND SLURRY PREPARATION WITH LIMITED PARTICLE SIZE

Ultrasonics, in conjunction with a centrifugal separation, was applied to recover over $50 \mathrm{~g}$ of alumina with particle diameters under $800 \mathrm{~A}$. The recovery, which represented over $50 \%$ of theoretical yield, was made from a 300-g sample of Linde Type B Alumina Polishing Powder.* The preparation was based on techniques previously developed for particle size distribution measurements. I Those techniques include ultrasonic dispersion of an aqueous slurry of the powder, and passing the slurry through a Sharples Laboratory Supercentrifuge** operating under force conditions which define the maximum particle size in the effluent. Electron micrographs of the product indicated that all particles larger than $800 \mathrm{~A}$ were removed. The $50 \%$ theoretical yield was calculated from a particle size distribution of the alumina, which indicated the weight fraction of particles with diameters less than $800 \mathrm{~A}$ present in the untreated polishing powder. The high yield of over 50\% was achieved by effectively applying the ultrasonics to disperse the powder in water. Without ultrasonics, no separation of the agglomerates of fine particles from the basically large particles could be made, resulting in a yield of only a few percent.

ULTRASONIC: DISPERSION OF KAOLINITE CLAY FOR PARTICLE SIZE DISTRIBU'IONN AND POWDER PREPARATION WITH LIMITED PARTICLE SIZE

Ultrasonics was applied to dispersing a Kãolinlte llay fur purlille size distribution determination, and for dividing the clay into three size fractions in usable (several-gram) quantities. Both procedures were based on the techniques developed for alumina, 1 and are summarized in the following sections.

Ultrasonic Dispersion for Particle Size Distribution

The clay sample was ultrasonically dispersed in water, and the suspension divided into size fractions using the Sharples Laboratory Supercentrifuge for the smaller particles, and a gravimetric procedure ${ }^{14}$ for the larger particles. The data from the two methods were combined to provide the particle size distribution from 300 to $10,000 \mathrm{~A}(0.03$ to $1 \mu$ ).

*Union Carbide Corporation, 4120 Kennedy Avenue, East Chicago, Indiana.

**Sharples Centrifuges, Pennsalt Corporation, 955 Mearns Road; Warminster, Pennsylvania. 
Ultrasonic Dispersion for Preparing Limited Size Fractions

Using the gravimetric and centrifugal procedures, the suspension was divided into three particle size ranges: under $0.25 \mu, 0.25$ to $I \mu$ and above $I \mu$. The size ranges were selected on the basis of the particle concentration in each range, determined from the particle size distribution made earlier. Starting with a $20 \mathrm{-g}$ sample, the fractions in the three ranges: below 0.25 $\mu, 0.25$ to $1 \mu$, and above $1 \mu$, yielded quantities of $1.7,4.0$, and $6.0 \mathrm{~g}$, respectively. Electron micrographs of the three size fractions confirmed the intended particle size range in each fraction.

The $11.7 \mathrm{~g}$ of recovered material, which represents $58.5 \%$ of the total sample, was obtained with two passes through the centrifuge. Since the target of $1 \mathrm{~g}$ of material for each size range was met, no further centrifuge passes were made. The remaining sediments were discarded.

The 58.5\% of recovered material clearly demonstrated the effectiveness of ultrasonic dispersion. Without ultrasonics, no effective recovery in the basic size ranges could be made, even with large numbers of passes through the centrifuge.

\section{ACKNOWLEDGMENTS}

The authors are pleased to acknowledge the contributions of V. H. Kiplinger who, using the principles outlined in this report, carried out the ultrasonic cledring, and radioactivity testing of the TRU-project fuel elements. In another project, $\mathrm{Mr}$. Kiplinger also carried out the ultrasonic cleaning of steel items in preparation for plating. The authors are also grateful to the many others who recognized the potential of ultrasonics, and requested evaluation in their development problems.

\section{RETRRENCES}

1. Lee, T. and Weber, C. W., "Particle Size Distribution Measurements in the 200 tin 1200 A Range, "Anal. Chem., 30 (1967) pp. 620-624.

2. Babikov, O. I., UZtrasonics and Its Industrial Applications, New York, Consultants Bureau (1960) p. 50.

3. Goobermun, G. I., ULtrasonics Theory and Application, New York, Hart (1969) p. 91.

4. Krasil'nikov, V. A., Sound and UZtrasound Waves, N. Kaner and M. Segal, tr., 3rd ed. Jerusalem, Israel Program for Scientific Translations (1963) p. 172.

5. Babikov, O. I., Ultrasonics and Its Industrial Applications, New York, Consultants Bureau (1960) p. 17. 
6. Hueter, T. F. and Bolt, R. H., Sonics, New York, Wiley (1955) pp. $260-261$.

7. Carlin, B., ULtrasonics, 2nd ed., New York, McGraw-Hill (1960) p. 167.

8. Hueter, T. F. and Bolt, R. H., Sonics, New York, Wiley (1955) pp. $238-241$.

9. Frederick, J. R., UZtrasonic Engineering, New York, Wiley (1965) pp. 138-140.

10. Gooberman, G..L., UZtrasonics Theory and Application, New York, Hart (1969) pp. 102-107.

11. Krasil!nikov, V. A., Sound and UZtrasound Waves, N. Kaner and M. Segal, tr., 3rd ed., Jerusalem, Israel Program for Scientific Translations (1963) p. 254.

12. Frederick, J. R., ULtrasonic Engineering, New York, Wiley (1965) pp. 118-119.

13. Ibid, p. 134 .

14. Stairmand, C. J., "A New Sedimentation Apparatus for Particle Size Analysis in the Sub-Sieve Range," Symposium on Particle Size Analysis, Trans. Inst. Chem. Engrs. (London), Supp 2. 25 (1947) p. 128. 


\section{DISTRIBUTION}

INTERNAL

1-2. Administrative Offices Stief, S. S. Winkel, R. A.

3. Barrier Manufacturing Div. Strang, F.

4. Computing Technology Center Kemper, B.

5. Engineering Division Patton, F. S.

6- 8. Fabrication \& Maint. Div. Elmore, E. Krieg, E. H., Jr. Studinger, I. A.

9-22. Gaseous Diffusion Dev. Div. Anderson, R. W. Collins, W. T. Fain, D. E. Farquharson, J. King, C. J. Kiplinger, $\mathrm{V} . \mathrm{H}$. McGill, R. M. Pashley, J. H. Randolph, M. H., Jr. Robbins, H. D. Stevens, R. H. Trammeli, H. E. Wheatley, S. J. White, D. E.

23-33. Laboratory Division Arendt, J. W. Barton, J. C. Hall, W. H. Junkins, J. H. Kwasnoski, T.

Lee, T. Napolitan, D. S. Yetit, G. S. Smith, L. A. Stewart, J. H., Jr. Weber, C. W.
34-42. Library Fraser, R. J.

43-44. Operations Analysis \& LRP Div. Lang, D. M. Pasquier, L. P.

45-46. Operations Division Dykstra, J., Jr. Legeay, A. J.

47-49. Separation Systems Div. Evans, E. C. Flanders, I. C. Keyser, R. M.

50-51. Shift Operations \& Security Div. Hartman, W. C. Hughes, M.

52. Sommerfeld, K. W.

53. Technical Director Wilcox, W. J., Jr.

54-56. ORGDP Records Department (RC)

57. U. S. Atomic Energy Commission Zachry, D. S.

58-64. Y-12 Plant Bernander, N. K. Griffin, J. D. Jackson, V. C. Shacter, J. Tewes, W. E. Williams, J. W. Yaggi, W. J.

EXTERNAL

65-230. TID-4500 